\title{
A CLASSE MÉDIA BRASILEIRA E O ARQUÉTIPO DO PRECONCEITO DE CLASSE
}

\section{ARTIGO ORIGINAL}

GIESBRECHT, Daniel Florence ${ }^{1}$

GIESBRECHT, Daniel Florence. A classe média brasileira e o arquétipo do preconceito de classe. Revista Científica Multidisciplinar Núcleo do Conhecimento. Ano 05, Ed. 02, Vol. 04, pp. 104-124. Fevereiro de 2020. ISSN: 2448-0959, Link de acesso: https://www.nucleodoconhecimento.com.br/historia/arquetipo-do-preconceito

\section{RESUMO}

Este artigo tem como objetivo elaborar uma reconstituição histórica, a partir do serial da longa duração, da formação da classe média brasileira e, também do seu arquétipo de preconceito de classe. Utilizamos como ponto de partida para nossa reflexão o fato de o Brasil ter vivido mais de trezentos anos de escravidão, o que legou a profusão de um imaginário racista, resultando em práticas preconceituosas e naturalizadas às populações afrodescendentes, além de ter se estendido para o cidadão pobre, em geral. Procuramos relacionar de forma historicista os objetos estudados aos conceitos sociológicos de socialização, além de caracterizarmos o ideário burguês da classe média e das elites brasileiras a partir da história das mentalidades. Pretendemos contribuir para um melhor entendimento dos entraves criados pela falta de práticas de alteridade nas relações sociais cotidianas.

Palavras-chave: Classe Social, preconceito, escravidão, exclusão social, alteridade.

${ }^{1}$ Doutorando em História Contemporânea; Mestre em Educação; Licenciatura em Ciências Sociais, Licenciatura em Pedagogia, Licenciatura em História. 


\section{INTRODUÇÃO}

Ao pesquisarmos indicadores econômicos sobre o potencial brasileiro, percebemos números consistentes e elevados, bastante competitivos comparados a outros países, tanto é que o Brasil, desde as décadas de 1960 até hoje, figura sempre entre os quinze países de maior produto interno bruto do globo.

Os números não se repetem se buscarmos dados referenciais a respeito dos índices de pobreza e desigualdade. Realidades alarmantes de distribuição de renda, altos índices de violência, mortalidade infantil, dentre outros, são facilmente percebidos aos olhos daqueles que percorrem o vasto território brasileiro, dando a impressão de estar passeando por dois mundos completamente distintos: o da opulência e o da miséria, uma ilusão de ótica de uma economia inserida de forma bem-sucedida no cenário mundial, mas que mascara uma complexa realidade social, que apresenta, em sua estrutura, marcas de profunda desigualdade.

Utilizaremos a palavra "pobreza" para nos referirmos à situação de milhões de pessoas que vivem no Brasil. Mas o conceito de pobreza, dependendo do contexto utilizado e de sua fatoração semântica, torna-se complexo e polissêmico. É, a partir dessa complexidade semântica, que propomos inferir nossa reflexão por meio deste artigo, relacionando a pobreza ao arquétipo da formação da classe média brasileira e suas inter-relações de classes.

No imaginário intrínseco da classe média brasileira em seus círculos de socialização, o imagético da pobreza transfigura-se numa percepção tão simplificada da realidade que os cerca, a ponto de o próprio indivíduo da classe subalterna, muitas vezes em estado de insegurança, adquirir de forma inconsciente o discurso da classe à qual não pertence e pela qual é explorado. Nessa situação, não é difícil nos deparamos com frases cotidianas do mais puro senso comum que procuram, a todo o momento, uma explicação para as mazelas das desigualdades do país: "Ele é pobre porque é vagabundo", "Pobre não gosta de trabalhar" ou, ainda, "Pobre não sabe fazer nada e não consegue aprender nada". 
Frases como essas acabam produzindo uma naturalização do social, isto é, apega-se ao caráter histórico e social de um fato reduzindo-o a um acontecimento natural. Dessa maneira, algo como carência deixa de ser encarada como resultado de uma estrutura montada a priori, que acaba por legitimar em sua práxis desigualdades, para ser considerada um atributo pessoal de um indivíduo.

Tomando-se como referência a ideia da naturalização das desigualdades e individualização das expectativas e fracassos ad hoc, torna-se necessária uma reflexão apurada dos fatores de classe que contribuem para a naturalização do arquétipo de inferiorização dos grupos sociais em desvantagem e que quebre os modelos pré-concebidos desde o advento do positivismo histórico do século XIX que, transformando as ciências sociais em natureza regida por leis imutáveis que escapam do controle humano, induzam ao conformismo, à aceitação passiva e resignada daquilo que é histórico e socialmente produzido (Sucupira, 1984). O arquétipo do pobre que fracassa cotidianamente, tão enraizado no imaginário coletivo brasileiro desde a colônia até a contemporaneidade, é nesse sentido uma operação ideológica, que serve para manter determinada ordem social, isto é, uma configuração da vida econômica que beneficia as classes sociais que produzem essa ideologia.

Utilizaremos em primeiro momento o referencial teórico de Souza (2019), o qual nos pareceu mais pertinente à crítica dos paradigmas que norteiam o pensamento social brasileiro, principalmente o do "culturalismo", em suas tentativas de explicar as origens das desigualdades no país. Também é nossa pretensão introduzir ao leitor as ideias que defenderemos a posteriori, principalmente a de que a estruturação do arquétipo mental da classe média brasileira é um dos grandes empecilhos à construção de uma país que consolide valores republicanos, e que crie condições da ampliação dos direitos à cidadania para milhões dos seus habitantes.

\section{POLISSEMIA DA POBREZA}

A pobreza é um fenômeno histórico e social. Isso significa que ela está relacionada intimamente com a estrutura da sociedade e com o modo que cada classe social se 
apropria dos bens produzidos ou da riqueza gerada. Não é um conceito fácil, mas podemos recorrer a diferentes critérios para tentarmos defini-lo.

O critério da renda pessoal ou familiar tem sido o mais utilizado no Brasil, porém acreditamos ser impreciso, devido a muitos fatores que, inclusive, vêm se agravando nos últimos anos, como, por exemplo, o crescimento das atividades informais, o que impede um controle efetivo da renda [2].

Além da renda, outro critério utilizado para configurar a pobreza consiste em verificar o que é considerado essencial para a reprodução da vida. Esse critério, portanto, a nosso ver, também é reducionista porque, devido a convenções internacionais, relaciona a pobreza apenas ao consumo de alimentos.

Parece-nos mais pertinente ampliar o conceito para "necessidades básicas", as quais não estariam restritas apenas à alimentação, mas incluiriam outros aspectos considerados indispensáveis para a reprodução material da existência, ampliando a ideia de pobreza para a incapacidade de alguém ou de uma família possuir meios que possibilitem o acesso a um conjunto de itens considerados essenciais para a sobrevivência. Esta também seria configurada no caso de a pessoa ou a família estar excluída do sistema educacional, visto que a escolarização na atualidade é imprescindível para adentrar no mercado de trabalho. De acordo com estudos de Rocha (2006), seria somente com a ampliação desses conceitos que poderíamos entender um país de dimensões continentais como o Brasil, imerso a enormes disparidades regionais.

Nossa ideia argumentativa é exatamente superar a visão material da constituição do conceito de pobreza para uma valorização psicológica e estrutural abstrata e inconsciente que, na construção histórica brasileira, legitima esse conceito ancorado em um arcabouço metodológico sustentado pelo arquétipo do preconceito, que inferioriza grupos sociais constituídos num país que teve, por mais de trezentos anos, as marcas diárias de uma economia e sociedade orientada às custas do trabalho escravo. 
O preconceito pode atender a diferentes interesses materiais, podendo ser: de classe, gênero, político, racial ou étnico e religioso. Mas para demonstrar a constituição do preconceito naturalizado pela classe média brasileira, indubitavelmente necessitamos conhecer as estruturas históricas que sintetizaram, por meio do passado précapitalista, as distâncias entre grupos sociais de uma sociedade que, da bipolaridade entre o senhor e o escravo, tramitou para uma organização mais complexa com o advento do capitalismo comercial e industrial, mas que sempre manteve o arquétipo do passado escravocrata.

A discriminação e o preconceito também podem produzir sentimentos de resignação e conformidade nas vítimas, as quais aceitam ser oprimidas e exploradas, como já alertava Sartre (1905-1980) em uma peça teatral intitulada A prostituta respeitosa [3] (1946). Parece-nos o caso brasileiro, com atitudes diárias da sua classe média de inferiorização dos menos favorecidos, acarretando com que estes introjetem o próprio preconceito e a ideia de fracasso, acreditando ser merecedores de tais discriminações.

\section{ORIGENS HISTÓRICAS DO PRECONCEITO DA CLASSE MÉDIA BRASILEIRA}

Entre os séculos XVI e XIX, o tráfico de escravos africanos para a América ligou os dois continentes no que se tornaria o mais lucrativo comércio da história brasileira. Escravos africanos estavam presentes nas mais diversas atividades do dia-a-dia. A naturalização da escravidão tornou-se algo tão enraizado nas estruturas da sociedade a ponto de ser muito improvável que esta fosse imaginada sem as divisões tradicionais daqueles que mandavam e dos que obedeciam. Esse modelo autoritário de relações sociais possibilita o entendimento das permanências simbólicas praticadas contra as populações mais pobres, mesmo depois da abolição da escravatura no final do século XIX.

Com o desenvolvimento do pensamento social brasileiro, principalmente a partir do início do século XX, tem-se tentado explicar o quadro dicotômico experimentando pela sociedade nativa ao longo de sua história. Acreditamos que, para essa tarefa, a teoria 
mais adequada, promovendo um melhor entendimento da construção dessa estrutura social, seja a da história serial, presente nas metodologias de Fernand Braudel[4]. Contemplar uma análise semiótica da formação das classes sociais brasileiras só é possível quando percebemos o serial da longa duração do escravismo, que validou na mentalidade cotidiana do país o arquétipo do preconceito, do distanciamento e da segregação, desde a Casa-grande até a senzala, que, com a transição para a modernidade da fase mercantil e industrial do capitalismo, corroborou uma nova forma de exploração, mas com a roupagem estrutural da antiga, segregando ricos e pobres dentro das grandes cidades, assim como nos círculos sociais.

Cabe ainda lembrar que o desenvolvimento de classes no Brasil, segundo Fausto (1997), está relacionado com a consolidação de uma classe proprietária, detentora da posse de terras e dos demais meios de produção. Em um país que já foi fundamentalmente agrícola, essa classe apropriava-se com facilidade da maior parte da riqueza produzida, já que explorava a mão de obra escravizada.

Sob os auspícios da sociedade colonial, desenvolveu-se de forma muito particular nas regiões em que se consolidou o sistema de plantation, relações sociais exteriores ao escravismo entre libertos e proprietários. Com a ausência de um sistema colonial direto, além de uma imensidão territorial, que dificultava a implementação de formas otimizadas de controle sob a tutela da coroa portuguesa, e da criação do sistema de distribuição de capitanias hereditárias - tentativa de conciliação público-privada no processo de colonização -, desenvolveram-se formas ambíguas, contraditórias e desregulamentadas de relações entre indivíduos de classes distintas. É nesse cenário que encontramos a figura do agregado.

Esse estrato intermediário de pessoas formalmente livres, entre senhores e escravos, é formado por homens e mulheres dependentes, tanto material como simbolicamente dos proprietários de terras e de gente. No sentido mais econômico e material, a dependência desse extrato social é inexorável. (...) Assim se constitui entre nós - como forma econômica, política e social - a figura do "agregado". Figura fundamental na literatura e na sociologia histórica brasileira, o agregado 
vai formar a primeira classe intermediária entre proprietários e despossuídos. (Sousa, 2018: 65-66).

Apesar de ainda distante do surgimento da classe média moderna brasileira, o grupo dos agregados, mesmo dependente e muitas vezes engrossando as estatísticas da população despossuída - bastasse a perda da proteção do seu "padrinho" -, é de suma importância para compreendermos a introjeção mental do preconceito entre as futuras classes sociais do Brasil moderno, dado que estas, dentro de um sistema de dominação autoritária do poder privado sobre o público, foi exatamente a casta que naturalizou os princípios de controle e violência praticados de forma, até certo ponto, sádica pelas elites ruralistas escravocratas, que inclusive delegaram também aos agregados direitos de oprimir aqueles vistos como "instrumentos que falavam", bestializados e desumanizados.

O fato que nos interessa a partir daqui é perceber que foi por intermédio dessa relação de interdependência entre senhores e agregados, além do monopólio da força estabelecido aquém do estado como organizador da sociedade, que o sentimento de desprezo pelo outro foi desembocar na constituição de um comportamento sádico com os escravizados e os mais humildes. Prazer pela violência são comumente verificados na história dessas classes intermediárias na sociedade brasileira, a ponto de serem mais intensos - aí se percebe o sadismo[5] como forma de reconhecimento de grupo, ou superioridade em relação ao outro - como prática cotidiana dos que denominamos homens livres. Cenas de humilhações, piadas, sátiras e comportamentos obtusos irão fazer parte do escopo de tratamento perpetrado aos marginalizados, os quais denominaremos de "escória" social.

Desde o início da atividade mineradora no crepúsculo do século XVII e durante praticamente todo o século XVIII, o Brasil experimentava o fenômeno da urbanização, concentrada principalmente na capitania de Minas Gerais. A sociedade estratificada do Nordeste açucareiro rendia-se a outra de caráter mais dinâmico e multifacetado em Vila Rica. Escravidão e liberdade caminhavam de mãos dadas numa economia interdependente, mas que proporcionava novas formas de ascensão social, inclusive aos negros forros ${ }^{[6]}$. A experiência mineira foi peculiar, na qual mestiços, negros e 
índios dispunham de um momento ímpar em que poderiam pôr em prática pela primeira vez os seus talentos, daí a grande quantidade de artistas, artesãos, contadores e o aparecimento de diversas outras profissões na região. Pela primeira vez na história do Brasil, um saber técnico mais expressivo aparecia para diferenciarse de uma sociedade construída pelo trabalho "bruto" e manual, abrindo o caminho para o surgimento da classe média moderna.

O início do século XIX foi o prenúncio de novos ares que viriam a sacudir o continente Europeu - e sua maior tempestade era Napoleão Bonaparte. As guerras iniciadas pelo imperador francês associavam-se, para além de suas ambições megalomaníacas, à nova forma assumida pelo sistema capitalista em sua etapa industrial. A França, inimiga histórica da Grã-Bretanha, iniciava um conflito de proporções continentais para abocanhar o seu quinhão, num agouro do que seria o fenômeno imperialista ainda a deflagrar-se em meados do século. Esse fato repercutiria de maneira direta e indireta no futuro de Portugal e consequentemente do Brasil, pois a estrutura administrativa metropolitana cruzaria os mares para estabelecer-se na colônia.

Esse processo, que a vinda da família real portuguesa veio consolidar, já estava prenunciado na descoberta das minas, na presença de algumas cidades coloniais de expressão, na necessidade de maior vigilância sobre a riqueza recém-descoberta e no maior controle, a partir de então, sobre o familismo e o mandonismo privado. Exemplo sintomático da passagem do poder do campo para as cidades é o caso das dívidas dos patriarcas rurais, antes incobráveis, a partir de então sendo pagas sob força policial. Tão importante quanto a mudança do centro economicamente dinâmico do Nordeste para o Sudeste foi a transformação social de largas proporções, implicando novos hábitos, novos papéis sociais, novas profissões e, ao fim e ao cabo, a construção de uma nova hierarquia social. (Souza, 2019: 61).

A urbanização acabou por representar um redimensionamento das estruturas de poder, fazendo com que este passasse do patriarcalismo individual para as mãos do estado que se organizava. Numa perspectiva weberiana, o monopólio legítimo da 
violência passava a se concentrar nas mãos dos aparelhos estatais - como a polícia, por exemplo - mesclando-se às prerrogativas das antigas formas de autoritarismo de classe, mas mantendo a prática do sadismo, antes de forma privada, agora perpetrado pelas forças públicas.

Com a abertura dos portos às nações amigas em 1808, decretada pelo até então príncipe regente $\mathrm{D}$. João $\mathrm{VI}$, e com a assinatura dos tratados de comércio e navegação de 1810, o Brasil passaria a experimentar transformações que impactariam de forma imediata sua estrutura colonial. O ambiente das cidades portuárias, principalmente Rio de Janeiro, Salvador e Recife se tornavam, do dia para a noite, centros agitados de comércio, com a entrada de produtos desconhecidos até então, que incentivaram a formação de uma estrutura monetária. Surgiam casas de câmbio e de comércio, agências de importação e exportação, bancos, enfim, uma infinidade de atividades até então desnecessárias no mundo do patriarcado rural, apenas experimentada em suas devidas proporções nas regiões mineradoras [7].

Mas a grande transformação social provocada por esse novo cenário europeizado das relações econômicas seria a entrada de milhares de imigrantes. Além dos cerca de 15 mil portugueses que chegaram juntos a família real, ingleses, alemães e franceses também advinham ao Brasil, por motivos desde econômicos até artísticos. $\mathrm{O}$ futuro país que nasceria em 1822 já assinalava características de estado independente.

Os imigrantes eram mão de obra livre que, somada aos trabalhadores livres nascidos no Brasil, comporiam a classe média moderna de que falávamos anteriormente. Uma classe diferente do antigo agregado rural, ocupando a porção intermediária da hierarquia social, mas sem a necessidade da proteção do seu compadre. Princípios liberais e de individualismo, que sopravam desde o século XVIII com a filosofia iluminista, adentravam o inconsciente do morador urbano. Uma espécie de self made man dos trópicos povoaria o imaginário citadino.

Com capitalismo mercantil abre-se um vácuo fundamental para sua manutenção e reprodução: a necessidade de capital cultural para operá-lo. Atividades comerciais, manufatureiras, burocráticas e de ensino - para ficarmos em poucos exemplos - 
necessitam de uma forma de conhecimento técnico e utilitário para sua operação, fato que contribuiria para a contraposição do trabalho manual, até agora comumente realizado pelo escravo ou pelos mais pobres. A classe média será o grupo que se apropriará desse saber e, por intermédio dele, se distanciará dos mais humildes, aqueles do trabalho pesado, do nível das bestas.

Aos abandonados e esquecidos, restam as tarefas desqualificadas, típicas da ralé. Estas, em grande medida, como no caso do trabalho doméstico, serão uma continuidade do escravismo, agora sob novas máscaras. A exploração direta da energia muscular - que mal nos distingue de um cavalo ou de uma mula -, com pouco conhecimento incorporado, é a característica distintiva, ainda que não a única, em relação aos trabalhadores com maior grau de qualificação técnica. (Souza, 2018: 74).

Tanto essa nova classe média, assim como a futura classe trabalhadora minimamente especializada, a qual denominaremos "baixa classe média", ou "proletária", tentarão a todo custo diferenciar-se da população vista como "escória", formada principalmente por negros e mestiços. Como não são detentoras dos meios de produção, tentarão ao menos imitar os valores simbólicos das elites, refletindo na obsessão pela europeização dos costumes e, por meio da educação formal e técnica, no distanciamento do trabalho manual, tão depreciado pelos valores ocidentais. Temos aí a nossa primeira manifestação concreta do preconceito incorporado pela classe média moderna do século XIX.

Questões endógenas e exógenas em relação à questão escravista brasileira foram determinantes para o amadurecimento inicial do processo de modernização das relações de trabalho e do amadurecimento do capitalismo industrial no século XIX. Desde a independência brasileira, a Inglaterra pressionava o recém-nascido estado nacional a demonstrar compromissos com a extinção gradual do tráfico negreiro praticado desde meados do século XVI. Movimentos internos liderados por intelectuais liberais, como por parte da própria elite cafeeira, debatiam abertamente a abolição. 
Tais fatos, em primeiro momento, poderiam apontar de maneira sui generis que o país, ao seu ritmo, poderia estar consolidando a sua transição do capitalismo comercial para o industrial, pois o cenário que se abria com a abolição da escravatura deslocaria não só uma enormidade de capital para os setores produtivos, como também a modernização das relações de classe, superando as amálgamas do sistema obsoleto escravocrata. Mas não foi isso o que ocorreu. A industrialização só se consolidaria no século seguinte, sob a batuta do estado, nos governos Getúlio Vargas e Juscelino Kubitschek, assim como no período ditatorial. A superação da escravidão, em seu campo simbólico, nunca seria superada.

Mesmo com a abolição consumada em 1888, fato que fez do Brasil o último país do mundo a acabar com a escravidão formal, o cenário perverso da violência física e simbólica continuava. Além disso, os negros libertos encontraram enormes dificuldades para a sua inserção no mercado de trabalho, pois ainda deveriam competir com a mão de obra imigrante, agora deliberadamente estimulada como prática estatal. Foi dentro dessa relação perversa de permanência que, com o passar do tempo, formou-se no Brasil, concomitantemente ao processo de urbanização, uma classe da população que foi completamente excluída dos princípios básicos da cidadania[8], e isso afetaria também suas próximas gerações, num efeito que denominaremos de "bola de neve turva[9]".

\section{INDUSTRIALIZAÇÃO EXCLUDENTE E O IMAGINÁRIO BURGUÊS DA CLASSE MÉDIA}

A velha ordem racial não desapareceu com o fim do trabalho escravo. Em vez disso, ela foi assimilada e integrada às novas estruturas sociais surgidas com o desenvolvimento do trabalho livre. Segundo Fernandes (1974), a revolução burguesa desencadeada com o fim da escravidão beneficiou apenas alguns segmentos da sociedade brasileira.

Entre os mais favorecidos, encontrava-se a porção "branca" da população de origem europeia, corroborando as teorias de branqueamento em voga no país. Esse grupo beneficiou-se de todas as transformações decorrentes do crescimento econômico, do 
surto industrializante, do processo de urbanização e do desenvolvimento de uma cultura citadina. A classe marginalizada integrada pelos afrodescendentes, permaneceu à margem da sociedade nacional, excluída em boa parte de todas as benfeitorias que essas transformações produziram. Esses fatos assinalavam que a desarticulação do trabalho escravo nas últimas décadas do século XIX não foi acompanhada por alterações substanciais na antiga ordem racial, caracterizada pelo preconceito e pela discriminação. A marginalização social de cerca de $50 \%$ dos brasileiros evidenciava claramente os limites da modernização econômica do país.

Com a manutenção dos meios de produção nas mãos da elite agroexportadora e da classe industrial incipiente, foi na cidade e em seu ambiente cosmopolita que o estilo de vida burguês se consolidou e, junto dele, todo o seu simbolismo. Foi com o surgimento da classe média urbana, principalmente aquela voltada às atividades intelectuais e financeiras, que o sentido da europeização e dos costumes se propagandeou. A incorporação de valores aristocráticos europeus pode ser percebida na adoção de um padrão de gosto e de luxo que procurava equiparar-se ao das camadas aristocráticas. Numa espécie de "canibalismo simbólico", a classe média mais abastada introjetava os preconceitos e o patriarcalismo, mas com uma roupagem que se dizia moderna.

Numa dialética simbólica, a classe média é um dos melhores elementos para percebermos como a esfera pública e privada eram fundamentais para sua autoafirmação, reconhecimento e distinção. Mesmo distante do conceito moderno de "meritocracia"[10], percebe-se como o arquétipo do mais "bem adaptado" ecoa no imaginário do burguês mediano. O mérito substituiu o direito de nascença como nova forma de diferenciação social, assim como a sofisticação intelectual, outro elemento que passou a distinguir a classe média das classes populares, ainda sem acesso à educação pública gratuita e de qualidade.

A generalização da família da classe média, na qual a mulher se encarregava dos cuidados com os filhos e dos afazeres domésticos - controlando o trabalho de numerosos empregados - e o homem participava das atividades do mundo empresarial, é um dos aspectos marcantes nesse sentido, pois dá ao indivíduo a 
sensação de continuidade, vendo em seus filhos a possibilidade de prosseguir com os negócios familiares. Portanto, a incorporação de valores aristocráticos, mais do que mero modismo, fazia parte do processo de consolidação da hegemonia política e social e da visão de mundo da classe média a respeito da sociedade [11].

Estabelecido o universo simbólico burguês da classe média brasileira, fica clara a percepção antagônica desta para com os demais grupos menos abastados e a sua tentativa de equipar-se simbolicamente às elites, estas sim verdadeiramente detentoras dos meios de produção e do real controle do país. Essa obsessão de se assemelhar às elites não será, a não ser em alguns casos, reconhecida na esfera pecuniária, portanto, resta a sua simbólica equiparação pelo status [12] ou prestígio social, podendo este ser obtido ou reconhecido por meio de três elementos: a ocupação produtiva (emprego), o consumo e o estilo de vida, todos plenamente adequados à moderna sociedade capitalista, ou, mais que isso, um complementando o outro.

Com a conquista do status na moderna sociedade meritocrática brasileira, novas formas de prestígio passam a fazer parte da nova hierarquia social. O mais importante, para a classe média, além da "virtude" da imitação, é distanciar-se das práticas cotidianas da "escória" social. Beber vinho em detrimento à cachaça, escutar música erudita ao invés da música popular, frequentar teatros, academias literárias e restaurantes caros para o exibicionismo da etiqueta, além das viagens internacionais - com direito a consultoria de pseudointelectuais, alimentando-se do sentimento ambíguo de repulsa ao que é nacional -, são pequenos exemplos dessa reducionista visão de mundo.

\section{CAPITAL CULTURAL, INSTITUIÇÕES SOCIAIS E PRECONCEITO}

Diferentemente da visão culturalista identificada no início do nosso texto como forma de explicação das desigualdades sociais e das relações de classes, subjetivando conceitos e justificando as diferenças apenas sob o ponto de vista material individual, necessitamos partir do entendimento sociológico das instituições primárias e 
secundárias de socialização para compreendermos o fenômeno do ódio de classe tão presente no cotidiano.

Em geral, a socialização tem início na família, instituição na qual o indivíduo aprende a língua e, por meio dela, a comunicar-se, a expressar necessidades, bem como sensações de desconforto ou bem-estar. Pesquisas psicológicas como as de Piaget (2005) confirmam a importância dos pais e dos demais membros da família na formação da personalidade infantil. Esses estudos apontam que no início do processo de socialização os membros familiares costumam ser mais decisivos que os indivíduos com quem a criança entra em contato apenas ocasionalmente. Encontramos aqui um problema: na organização da sociedade escravocrata brasileira tudo se fez para evitar a construção de laços de solidariedade entre as populações escravizadas, e a primeira instituição combatida foi a família, comprometendo essa etapa da socialização. Nota-se que dificilmente havia espaço para a constituição de laços sociais primários no cárcere, desconsiderando as necessidades psíquicas e emocionais dos cativos.

A dificuldade da organização familiar não é mero fenômeno do passado escravista, mas permanece, nas devidas proporções, entre as populações mais humildes, nos filhos, netos e bisnetos das antigas gerações de aviltados. Tudo isso trará profundas consequências nas relações secundárias futuras, principalmente na aprendizagem da escola, ocasionando menor chance de prestígio no mercado de trabalho. Famílias mais fragilizadas geralmente são taxadas de "desajustadas" pelas classes mais altas, principalmente pelo discurso generalista da classe média que, desde o berço, teve condições de construir laços de solidariedade que serão determinantes para o sucesso futuro.

O caso atual da exploração da ralé brasileira para poupar tempo de tarefas domésticas sujas e pesadas - que lhe permite utilizar o tempo "roubado" a preço vil em atividades mais produtivas e bem remuneradas - mostra uma funcionalidade da miséria clara como a luz do Sol. Essa luta de classes silenciosa exime toda uma classe dos cuidados com os filhos e da vida doméstica, transformando o tempo poupado em dinheiro 
e aprendizado qualificador. A classe roubada, no caso, é condenada eternamente a desempenhar os mesmos papéis secularmente servis. (Souza, 2019: 85).

Poupar tempo nas tarefas braçais e investir tempo em atividades intelectuais. Como resultado, maior capacitação profissional e, consequentemente, maior prestígio social; institui-se um círculo que nada tem relação com mérito, ou capacidade pessoal, mas sim com apropriação de maior capital cultural.

Segundo Bourdieu (2004), os filhos de famílias abastadas tendem a apresentar rendimento escolar superior ao dos jovens de famílias pertencentes às classes populares. Na maior parte dos casos, isso ocorre porque os alunos oriundos das classes dominantes dispõem de um capital cultural que os outros não tiveram condições de acumular, não apenas na escola, mas também da formação cultural dos pais, que ensinariam aos filhos as demandas para manter e expandir sua situação social privilegiada. As crianças em situação de fragilidade social não dispõem dessa rede de proteção, tendendo a enfrentar muito mais dificuldades por não possuírem os conhecimentos e as práticas valorizadas pela cultura dominante. Eles não participariam dos valores cultivados por essas elites e, por essa razão, tenderiam a considerar o aprendizado escolar uma forma de violência contra seus valores e práticas sociais, explicando os altos índices de evasão da escola brasileira [13].

$\mathrm{Na}$ escola, talvez tenhamos a melhor percepção prática da violência simbólica. Nela, por exemplo, é comum o aluno oriundo das classes populares deparar-se com uma linguagem, uma prática cultural e valores que desconhece por não possuir determinada herança cultural, ou, como aponta Bourdieu, um capital cultural que o capacite a entendê-los ou assimilá-los, comprometendo seu rendimento escolar, transformando-se num impeditivo imposto pela própria instituição e deslegitimando o desempenho desse aluno. Apesar disso, o estudante não percebe que seu baixo rendimento escolar é determinado por fatores sociais e por isso acaba por introjetar muitas vezes o fracasso, comprometendo sua autoestima em um momento crucial de sua formação não só acadêmica, mas humana. 
Tendo como ponto de referência o acesso e a continuidade no sistema de educação formal como uma das principais chances apregoadas por uma sociedade que se julga "meritocrática", encontramos um exemplo sútil de como as limitações impostas pelo passado escravocrata se perpetuam, mas de forma quase invisível. Se antigamente poderíamos perceber tudo explicitamente desigual, devido ao fenótipo e à exclusão explicita dos escravos às instituições, hoje, tudo se aparenta corrigido devido à criação de um sistema de educação pública, deslocando todas as responsabilidades de sucesso ou insucesso para o âmbito individual. Tapa-se aí o sol com a peneira [14], pois a maioria das populações carentes são excluídas de capital cultural, apropriado deliberadamente pela classe média e pelas elites, além de ter acesso a um sistema de serviços público ineficiente.

No mundo capitalista, a falta de sucesso material Ihe condena ao status do fracasso. Imagine então ser desprovido de capital material e também de capital cultural? Como as formas de ascensão de classe no sistema predatório do capital não são fáceis, o ciclo reprodutivo da pobreza e da exclusão tende a se perpetuar desde o nascimento para aqueles que são oriundos das classes mais pobres. Isso resultará ao sujeito, além de menores chances de constituir uma formação que the dê condições de competir com os filhos das classes abastadas, muito mais chance de sofrer todos os tipos de violência física e simbólica.

Como a reprodução da desigualdade de classe desde o berço é reprimida tanto consciente quanto inconscientemente, é o estereótipo do negro, facilmente reconhecível, que identifica de modo fácil o inimigo a ser abatido e explorado. O "perigo negro" usado como senha para massacrar indefesos e quilombolas durante séculos é continuado por outros meios no massacre aberto, e hoje aplaudido sem pejo, de pobres e negros em favelas e presídios. E não só isso. Como houve continuidade sem quebra temporal entre a escravidão - que destrói a alma por dentro, humilha e rebaixa o sujeito, tornando-o cúmplice da própria dominação - e a produção de uma ralé de inadaptados ao mundo moderno, nossos excluídos herdaram, sem solução de continuidade, 
todo o ódio e o desprezo covarde pelos mais frágeis e com menos capacidade de se defender. (Souza, 2019: 88).

Mas por que tamanha desigualdade parece não ser percebida pela classe média brasileira? Como dizíamos no início deste artigo, a teoria de classes sociais tomada por critérios de renda é insuficiente para entendermos uma composição social complexa como a brasileira, fragilizada pelas consequências do seu passado escravocrata. Em nossa opinião é necessária a superação do mero viés econômico para adentrarmos a partir da história das mentalidades [15]. Um cidadão de classe média tende a pensar como sua classe, portanto não possuiria base instrumental para percepção do outro, tornando o exercício da alteridade sofrível ou, muitas vezes, inalcançável. Essa ausência de dialética produz pessoas preconceituosas, desprovidas de percepção do outro, num país inserido no século XXI dentro de uma ordem de mercado competitiva, que ultrapassa a esfera econômica, atingindo a social, de pensamento e percepção de mundo. O colonialismo mental acaba por dominar mentes, mantendo o status quo.

\section{CONSIDERAÇÕES FINAIS}

Traçar uma reconstituição histórica da formação da classe média brasileira e de seu arquétipo de preconceito não é tarefa fácil devido a ambiguidade do próprio conceito de classe social. O fator que acreditamos essencial para essa compreensão é a escravidão passada, que interfere de maneira dramática no entendimento do presente e do tecido social brasileiro. É somente no serial da longa duração que podemos construir a narrativa aqui apresentada e a nossa argumentação para o entendimento das classes a partir do contexto sociocultural, rompendo com o economicismo tradicional das teorias de classes, ora interpretadas por pensadores liberais, ora por pensadores marxistas.

Identificando a importância do passado escravocrata para configuração das mentalidades de classe perpetuadas pelas instituições sociais, podemos perceber as desigualdades e os estereótipos socialmente constituídos que parecem se reproduzirem ad infinitum. 
A família, a escola, as organizações, tudo isso promove ao longo da nossa história a reprodução dos privilégios de grupos elitistas e da classe média, que se camufla com a tinta das análises pseudocientíficas da meritocracia, em um dos países mais desiguais do planeta. A falácia de que é possível a ascensão quase que inata para alguns em detrimento de outrem foi incorporada ao imaginário da classe média de forma tão consistente que conseguiu penetrar inclusive nas camadas populares, no fenômeno que tratamos no texto sobre a introjeção do preconceito.

Nascer na classe média e classe média alta é quase sinônimo da reprodução do sucesso de gerações passadas e da incorporação de privilégios que farão total diferença no futuro. Parecem fatos banais, mas adquirir desde cedo a disciplina de estudo, frequentar determinados ambientes, conviver com pessoas providas do capital cultural necessário para se destacar nas relações sociais, cursar uma língua estrangeira no contraturno escolar e estar bem alimentado são pequenos exemplos de privilégios que, somados a centena de outros, moldarão o futuro cidadão bem sucedido, como se seu mérito pessoal tivesse sido o grande diferencial de tal conquista.

Naturalizar a violência cotidiana contra pobres, negros, mulheres, dentre outras minorias, é sintomático da violência que moldou a história brasileira. Os ecos da escravidão se fazem escutar em cada morte na favela, em cada agressão praticada pela polícia, em cada piada no almoço de domingo contada nas mesas de famílias que já naturalizaram o racismo como algo moralmente aceitável, como se não aviltasse a dignidade humana, transformando assim a realidade da classe média numa jaula de medos, angústias e ódio sistêmico.

\section{REFERÊNCIAS}

BONFIM, Paulo Ricardo. Educar, higienizar e regenerar: uma história da eugenia no Brasil. São Paulo: Paco, 2019.

BOURDIEU, Pierre. A economia das trocas simbólicas. São Paulo: Perspectiva, 2004. 
BRAUDEL, Fernand. Escritos sobre a história. São Paulo: Perspectiva, 1978.

CARVALHO, José Murilo de. Cidadania no Brasil: o longo caminho. São Paulo: Civilização Brasileira, 2003.

DOWBOR, Ladislau. A era do capital improdutivo. São Paulo: Editora Novas Palavras, 2017.

FAUSTO, Bóris. História do Brasil. 6. ed. São Paulo: Edusp/FDE, 1997. . História concisa do Brasil. São Paulo :Edusp, 2002.

FERNANDES, Florestan. Revolução burguesa no Brasil: ensaio de interpretação sociológica. Rio de Janeiro: Zahar, 1974.

FROMM, Erich. Anatomia da destrutividade humana. Rio de Janeiro: Zahar, 1975.

KENNETH, Maxwell. A devassa da devassa. São Paulo: Paz e Terra, 1995.

KLEIN, Naomi. Sem logo: a tirania das marcas em um planeta vendido. Rio de Janeiro: Record, 2002.

PARSONS, Talcott. Social structure \& person. USA: Free Press, 2007.

PIAGET, Jean. A representação do mundo na criança. Curitiba: Ideias e Letras, 2005.

ROCHA, Sônia. Pobreza no Brasil. Rio de Janeiro: FGV, 2006.

SARTRE, Jean Paul. A prostituta respeitosa. Campinas: Papirus, 1992.

SOUZA, Jessé. A classe média no espelho. Rio de Janeiro: Estação Brasil, 2018. . A elite do atraso. Rio de Janeiro: Estação Brasil, 2019.

SUCUPIRA, Eduardo. Introdução ao pensamento dialético. São Paulo: Alfa-Omega, 1984. 
VOVELLE, Michel. Ideologias e mentalidades. São Paulo: Brasiliense, 1987.

WEBER, Max. A ética protestante e o espírito do capitalismo. São Paulo: Companhia das Letras, 2007.

YOUNG, Michael. The rise of meritocracy. United Kingdom: Transaction Pub, 1994

\section{APÊNDICE A}

\begin{tabular}{|c|c|c|c|c|c|c|c|c|c|c|}
\hline \multirow{3}{*}{ Grandes Regiões e car acteristicas selecionadas } & \multicolumn{10}{|c|}{$\begin{array}{l}\text { Taxa de frequência liquida a estabelecimento de ensino da população residente de } 6 \text { a } 24 \text { anos de idade, por grupos de idade e nivel de } \\
\text { ensino (\%) }\end{array}$} \\
\hline & \multicolumn{2}{|c|}{$\begin{array}{l}6 \text { a } 14 \text { anos, no ensino } \\
\text { fundamental }\end{array}$} & \multicolumn{2}{|c|}{$\begin{array}{l}6 \text { a } 10 \text { anos, nos anos } \\
\text { iniciais do ensino } \\
\text { fundamental }\end{array}$} & \multicolumn{2}{|c|}{$\begin{array}{l}11 \text { a } 14 \text { anos, nos anos } \\
\text { finais do ensino } \\
\text { fundamental }\end{array}$} & \multicolumn{2}{|c|}{$\begin{array}{l}15 \text { a } 17 \text { anos, no ensino } \\
\text { médio }\end{array}$} & \multicolumn{2}{|c|}{$\begin{array}{l}18 \text { a } 24 \text { anos, no ensino } \\
\text { superior }\end{array}$} \\
\hline & Taxa & $\mathrm{CV}(\%)$ & Taxa & $\mathrm{CV}(\%)$ & Taxa & $\mathrm{CV}(\%)$ & Taxa & $\mathrm{CV}(\%)$ & Taxa & CV (\%) \\
\hline Brasil & 97,0 & 0,1 & 95,5 & 0,2 & 85,9 & 0,3 & 68,5 & 0,6 & 23,2 & 1,3 \\
\hline Norte & 96,6 & 0,2 & 95,0 & 0,4 & 79,4 & 1,0 & 59,7 & 1,8 & 17,7 & 3,3 \\
\hline Nordeste & 96,8 & 0,1 & 95,3 & 0,2 & 82,0 & 0,6 & 60,7 & 1,1 & 16,8 & 2,9 \\
\hline Sudeste & 97,3 & 0,2 & 95,7 & 0,3 & 89,2 & 0,5 & 76,5 & 1,0 & 25,8 & 2,4 \\
\hline Sul & 97,4 & 0,2 & 96,1 & 0,3 & 89,6 & 0,6 & 69,6 & 1,4 & 29,1 & 2,4 \\
\hline Centro-Oeste & 96,8 & 0,3 & 95,0 & 0,4 & 88,4 & 0,9 & 70,4 & 1,7 & 30,1 & 2,9 \\
\hline \multicolumn{11}{|l|}{ Situação do domicílio } \\
\hline Urbana & 97,1 & 0,1 & 95,5 & 0,2 & 87,2 & 0,3 & 70,6 & 0,7 & 25,6 & 1,4 \\
\hline Rural & 96,9 & 0,2 & 95,6 & 0,2 & 79,6 & 0,7 & 57,4 & 1,3 & 8,3 & 3,5 \\
\hline \multicolumn{11}{|l|}{ Sexo } \\
\hline Homem & 96,9 & 0,1 & 95,3 & 0,2 & 83,5 & 0,5 & 63,6 & 0,9 & 19,7 & 1,8 \\
\hline Mulher & 97,2 & 0,1 & 95,7 & 0,2 & 88,3 & 0,4 & 73,7 & 0,7 & 26,8 & 1,5 \\
\hline \multicolumn{11}{|l|}{ Cor ou raça (1) } \\
\hline Branca & 97,3 & 0,1 & 95,8 & 0,2 & 89,5 & 0,4 & 76,6 & 0,8 & 32,9 & 1,6 \\
\hline Preta ou parda & 96,9 & 0,1 & 95,3 & 0,2 & 83,7 & 0,4 & 63,5 & 0,9 & 16,7 & 1,8 \\
\hline \multicolumn{11}{|l|}{$\begin{array}{l}\text { Classes de percentual de pessoas em ordem } \\
\text { crescente de rendimento domiciliar per capita }\end{array}$} \\
\hline Até $20 \%$ & 96,6 & 0,2 & 94,9 & 0,2 & 78,9 & 0,6 & 54,7 & 1,3 & 6,6 & 4,5 \\
\hline Mais de $20 \%$ até $40 \%$ & 96,9 & 0,2 & 95,4 & 0,3 & 85,3 & 0,6 & 65,3 & 1,2 & 12,0 & 3,3 \\
\hline Mais de $40 \%$ até $60 \%$ & 97,5 & 0,2 & 96,1 & 0,3 & 90,1 & 0,6 & 73,9 & 1,0 & 20,1 & 2,6 \\
\hline Mais de $60 \%$ até $80 \%$ & 97,5 & 0,3 & 95,9 & 0,5 & 93,0 & 0,6 & 81,1 & 1,2 & 32,3 & 2,1 \\
\hline Mais de $80 \%$ & 97,8 & 0,3 & 96,1 & 0,5 & 95,0 & 0,5 & 90,7 & 0,8 & 58,3 & 1,5 \\
\hline
\end{tabular}

Fonte: IBGE Pesquisa Nacional por Amostra de Domicilios Continua, 2017, segundo trimestre.

Nota: (1) Não são apresentados resultados para amarelos, indigenas e pessoas sem declaração de cor ou raça. 


\section{APÊNDICE B}

\begin{tabular}{|c|c|c|c|c|c|c|c|c|c|c|c|c|}
\hline \multirow{4}{*}{$\begin{array}{l}\text { Grandes Regiöes e } \\
\text { Unidades da Federação }\end{array}$} & \multicolumn{12}{|c|}{ Distribuição percentual da população, por classes de percentual de pessoas em ordem crescente de rendimento real efetivo domic iliar per capita e cor ou raça (\%) } \\
\hline & \multicolumn{4}{|c|}{ Total } & \multicolumn{4}{|c|}{ Entre os $10 \%$ com menores rendimentos } & \multicolumn{4}{|c|}{ Entre os $10 \%$ com maiores rendimentos } \\
\hline & \multicolumn{2}{|c|}{ Branca } & \multicolumn{2}{|c|}{ Preta ou parda } & \multicolumn{2}{|c|}{ Branca } & \multicolumn{2}{|c|}{ Preta ou parda } & \multicolumn{2}{|c|}{ Branca } & \multicolumn{2}{|c|}{ Preta ou parda } \\
\hline & Percentual & CV $(\%)$ & Percentual & CV (\%) & Percentual & CV (\%) & Percentual & CV (\%) & Percentual & CV $(\%)$ & Percentual & CV (\%) \\
\hline Brasil & 43,6 & 0,5 & 55,4 & 0,4 & 23,9 & 1,8 & 75,2 & 0,6 & 71,7 & 0,8 & 26,3 & 2,3 \\
\hline Norte & 20,1 & 1,9 & $\mathbf{7 8 , 4}$ & 0,5 & 12,5 & 6,8 & 84,8 & 1,3 & 34,2 & 3,8 & 64,4 & 1,9 \\
\hline Rondônia & 31,2 & 3,0 & 68,2 & 1,4 & 23,6 & 9,3 & 75,2 & 2,9 & 40,9 & 7,9 & 58,4 & 5,5 \\
\hline Acre & 19,1 & 4,3 & 79,9 & 1,1 & 14,1 & 12,5 & 85,3 & 2,1 & 31,8 & 8,2 & 67,7 & 3,8 \\
\hline Amazonas & 18,1 & 4,7 & 79,5 & 1,2 & 11,0 & 13,1 & 86,2 & 2,0 & 38,2 & 9,8 & 60,5 & 5,8 \\
\hline Roraima & 21,5 & 5,6 & 72,4 & 2,0 & 14,6 & 17,7 & 71,3 & 7,3 & 40,9 & 8,4 & 55,5 & 6,5 \\
\hline Pará & 18,2 & 3,3 & 80,6 & 0,8 & 11,8 & 12,6 & 85,8 & 2,2 & 30,0 & 5,5 & 68,9 & 2,4 \\
\hline Amapá & 19,3 & 6.5 & 80,3 & 1.6 & 10,6 & 26.6 & 87.7 & 3,6 & 25.9 & 13.4 & 73,4 & 4.8 \\
\hline Tocantins & 23,7 & 4,7 & 75,3 & 1,5 & 14,8 & 19,0 & 84,4 & 3,4 & 42,5 & 6,4 & 56,2 & 4,7 \\
\hline Nordeste & 24,8 & 1,2 & 74,6 & 0,4 & 18,7 & 3,3 & 80,8 & 0,8 & 42,8 & 2,7 & 56,4 & 2,0 \\
\hline Maranhão & 18,5 & 2,6 & 80,8 & 0,6 & 15,7 & 6,9 & 83,9 & 1,3 & 31,5 & 5,5 & 67,4 & 2,6 \\
\hline Pauí & 20,5 & 4,8 & 79,4 & 1,2 & 18,6 & 11,0 & 81,2 & 2,5 & 40,9 & 7,6 & 58,6 & 5,5 \\
\hline Ceará & 27,5 & 2,2 & 71,9 & 0,8 & 20,4 & 6,2 & 79,1 & 1,6 & 46,9 & 4,3 & 52,6 & 3,8 \\
\hline Rio Grande do Norte & 36,7 & 2,6 & 63,1 & 1,5 & 30,6 & 7,1 & 69,1 & 3,1 & 50,9 & 5,5 & 48,8 & 5,8 \\
\hline Paraba & 33,8 & 3,0 & 66,1 & 1,5 & 30,1 & 7,2 & 69,8 & 3,1 & 54,1 & 5,4 & 45,7 & 6,3 \\
\hline Pernambuco & 30,7 & 3,0 & 68,5 & 1,4 & 23,2 & 8,3 & 76,5 & 2,5 & 51,5 & 5,8 & 47,4 & 6,2 \\
\hline Alagoas & 23,4 & 2,8 & 76,1 & 0,9 & 21,8 & 6,3 & 77,9 & 1,8 & 36,1 & 6,6 & 63,5 & 3,8 \\
\hline Sergipe & 20,8 & 5,4 & 78,3 & 1,4 & 13,6 & 13,9 & 85,7 & 2,2 & 36,6 & 12,4 & 61,7 & 7,3 \\
\hline Bahia & 19,2 & 3,9 & 80,2 & 0,9 & 14,7 & 9,4 & 84,6 & 1,6 & 35,3 & 9,1 & 63,6 & 4,9 \\
\hline Sudeste & 51,2 & 0,9 & 47,6 & 1,0 & 35,2 & 2,8 & 64,2 & 1,5 & 78,1 & 1,1 & 19,0 & 4,6 \\
\hline Minas Gerais & 40,4 & 1,7 & 59,3 & 1,2 & 24,5 & 5,5 & 75,2 & 1,8 & 64,8 & 2,6 & 34,8 & 4,8 \\
\hline Espírito Santo & 39,2 & 2,6 & 60,2 & 1,7 & 22,5 & 10,6 & 77,2 & 3,1 & 64,5 & 3,0 & 35,2 & 5,6 \\
\hline Rio de Janeiro & 43,8 & 1,7 & 55,7 & 1,3 & 28,4 & 5,2 & 71,2 & 2,1 & 74,5 & 1,9 & 24,8 & 5,8 \\
\hline São Paulo & 60,1 & 1,2 & 38,1 & 2,0 & 46,8 & 3,7 & 52,4 & 3,3 & 83,1 & 1,4 & 12,3 & 9,0 \\
\hline Sul & 75,6 & 0,5 & 23,7 & 1,7 & 59,3 & 2,1 & 39,9 & 3,2 & 91,3 & 0,6 & 7,9 & 6,9 \\
\hline Paraná & 67,2 & 1,1 & 31,7 & 2,3 & 52,2 & 3,8 & 46,7 & 4,3 & 86,7 & 1,3 & 11,4 & 9,4 \\
\hline Santa Catarina & 82,8 & 0,7 & 16,9 & 3,4 & 68,5 & 2,9 & 31,2 & 6,4 & 92,8 & 0,9 & 6,8 & 11,7 \\
\hline Rio Grande do Sul & 79,6 & 0,9 & 20,0 & 3,5 & 64,2 & 3,3 & 35,2 & 6,1 & 94,4 & 0,9 & 5,5 & 15,4 \\
\hline Centro-Oeste & 36,3 & 1,4 & 62,6 & 0,8 & 25,0 & 4,5 & 74,0 & 1,5 & 56,2 & 3,4 & 41,0 & 4,0 \\
\hline Mato Grosso do Sul & 43,2 & 2,6 & 55,5 & 2,1 & 28,9 & 8,7 & 69,1 & 3,7 & 65,0 & 3,6 & 34,1 & 6,8 \\
\hline Mato Grosso & 31,8 & 3,2 & 67,0 & 1,5 & 23,7 & 12,3 & 74,9 & 3,9 & 54,4 & 4,8 & 43,9 & 6,0 \\
\hline Goiás & 35,7 & 2,2 & 63,6 & 1,2 & 23,9 & 7,4 & 75,8 & 2,3 & 51,6 & 4,2 & 47,7 & 4,6 \\
\hline Distrito Federal & 36,7 & 4,1 & 61,6 & 2,4 & 22,8 & 11,0 & 76,5 & 3,3 & 59,3 & 10,5 & 29,1 & 10,0 \\
\hline
\end{tabular}

\section{APÊNDICE C - REFERÊNCIAS DE NOTA DE RODAPÉ}

2. Para o entendimento da financeirização do capitalismo e suas repercussões no mundo do trabalho, vide DOWBOR, Ladislau. A era do capital improdutivo. São Paulo: Editora Novas Palavras, 2017.

3. SARTRE, Jean Paul. A prostituta respeitosa. Campinas: Papirus, 1992. Nessa peça, o autor retrata como a introjeção do preconceito, incorporada pela vítima, naturaliza-se no interior da sociedade do sul dos Estados Unidos.

4. BRAUDEL, Fernand. Escritos sobre a história. São Paulo: Perspectiva, 1978.

5. FROMM, Erich. Anatomia da destrutividade humana. Rio de Janeiro: Zahar, 1975. 
6. Uma das obras mais consistentes e rica em fontes primárias sobre a organização das regiões mineradoras é de KENNETH, Maxwell. A devassa da devassa. São Paulo: Paz e Terra, 1995.

7. Sobre o período em questão, vide FAUSTO, Bóris. História concisa do Brasil. São Paulo: Edusp, 2002.

8. Para um melhor entendimento sobre a construção do processo da cidadania brasileira, vide CARVALHO, José Murilo de. Cidadania no Brasil: o longo caminho. São Paulo: Civilização Brasileira, 2003.

9. Utilizamos metaforicamente a expressão "bola de neve turva", pois negros, mestiços, indígenas, pardos, além é claro da população branca marginalizada, engrossavam o contingente da "escória" segregada da sociedade hierarquizada brasileira. Durante o século XIX, o Racismo Científico e os princípios da eugenia encontravam na América, particularmente nos eugenistas norte-americanos, seus principais porta-vozes. Apesar do preconceito no Brasil erroneamente ser restringido às questões fenotípicas, é considerável o papel desempenhado pelos eugenistas no estímulo às políticas de branqueamento, assumidas deliberadamente pelo governo brasileiro com o intuito de purificar a genética da população. Isso contribuiu de forma direta com o estímulo ao racismo e à animalização dos indivíduos considerados "inferiores". BONFIM, Paulo Ricardo. Educar, higienizar e regenerar: uma história da eugenia no Brasil. São Paulo: Paco, 2019.

10. No Brasil, o conceito de "meritocracia" permeia o senso comum e a demagogia. A nosso ver, só se compreende "meritocracia" se adentrarmos a sua origem na literatura em que o conceito nasce de forma satírica e irônica. Ver YOUNG, Michael. The rise of meritocracy. United Kingdom: Transaction Pub, 1994.

11. "Com o advento da cultura de massa no século $X X$, o capitalismo cria um novo simbolismo de falsa inclusão, introduzindo na sociedade contemporânea o que denominamos de "supressão da subjetividade", suscitando o desenvolvimento do chamado "comportamento mimético", ou seja, o indivíduo teria deixado de 
desenvolver uma personalidade própria, original, que o colocasse em conflito e tensão com a realidade social estabelecida." KLEIN, Naomi. Sem logo: a tirania das marcas em um planeta vendido. Rio de Janeiro: Record, 2002.

12. Tomamos como referência o conceito de status em WEBER, Max. A ética protestante e o espírito do capitalismo. São Paulo: Companhia das Letras, 2007.

13. Conforme os apêndices A e B, nota-se com clareza de dados as mazelas históricas do processo de exclusão das populações pretas e pardas em seu percurso educacional, distanciando estes grupos dos mecanismos de acessos exigidos pela sociedade contemporânea para uma vida digna, que demanda uma melhor colocação profissional, comprometendo seus rendimentos e sua capacidade de inserção no mundo capitalista.

14. Expressão popular brasileira utilizada para descrever medidas inefetivas para determinados problemas.

15. VOVELLE, Michel. Ideologias e mentalidades. São Paulo: Brasiliense, 1987.

Enviado: Dezembro, 2019.

Aprovado: Fevereiro, 2020. 